Сидоров А. В.

Аннотация. Цель исследования - охарактеризовать практику изучения англоязычных авторских псевдонимов, датируемых XVIII-XXI вв. В статье рассматривается отечественный и зарубежный опыт научного осмысления псевдонимии, а также приводятся примеры создания псевдонимов на основе различных языковых единиц. Научная новизна исследования заключается в анализе ономастического материала с применением по́левого метода и систематизации разрозненных научных сведений об англоязычной литературной псевдонимии. В результате доказано, что существует три основных подхода к изучению англоязычных авторских псевдонимов (ономатографический, литературоведческий и ономастический), а сами псевдонимы, образуя по́левую структуру, бывают трех видов - проприальные, апеллятивные и проприально-апеллятивные.

\title{
EN Place of English-Language Literary Pseudonyms in the Onymic System and Approaches to Their Study
}

\author{
Sidorov A. V.
}

\begin{abstract}
The purpose of the research is to characterise the practice of studying English-language literary pseudonyms from the XVIII-XXI centuries. The paper examines the Russian and foreign experience of scholarly understanding of pseudonyms, as well as provides examples of creating pseudonyms on the basis of various language units. Scientific novelty of the research lies in analysing onomastic material using the field method and systematising scattered scientific information regarding English-language literary pseudonymy. As a result, it has been proved that there are three main approaches to studying English-language literary pseudonyms (onomatographic, literary and onomastic), while the pseudonyms themselves, forming a field structure, are of three types, i.e. proprial, appellative and proprial-appellative.
\end{abstract}

\section{Введение}

Актуальность исследования обусловлена активным проникновением псевдонимии в различные сферы культуры (литературу, СМИ, шоу-бизнес, изобразительное искусство). В современных реалиях псевдоним уже не просто отражает разнообразные грани авторской лингвокреативности, он становится охраняемым законом объектом интеллектуальной собственности, широко известным брендом, неотъемлемой составляющей писательской деятельности, осуществляемой в виртуальном пространстве. Однако вопрос о последовательном описании процесса изучения псевдонимии в англоязычной литературе все еще остается открытым. В этой связи настоящее исследование призвано охарактеризовать в диахронии подходы к теоретико-практическому анализу рассматриваемых ономастических единиц.

Для достижения поставленной цели исследования предполагается решить следующие задачи: во-первых, обозначить и описать подходы к изучению англоязычных авторских псевдонимов; во-вторых, определить место псевдонимов в системе онимов с позиций применяемого в ономастических исследованиях по́левого метода.

В статье применяются следующие методы исследования: стратиграфический, библиографический, по́левый и этимологический.

Теоретической базой исследования послужили труды отечественных и зарубежных лингвистов (В. Г. Адмони (1964), В. В. Виноградова (1961), А. В. Суперанской (2009; Суперанская, Сталтмане, Подольская и др., 2019), Н. В. Подольской (1978), В. И. Супруна (2000), J. Raven (2003), M. Ezell (1994), A. Fowler (2012)), посвященные исследованию различных аспектов литературной псевдонимии.

Материалом исследования служат псевдонимы англоязычных авторов XVIII-XXI вв., содержащиеся в тематических словарях (Т. J. Carty (2000), А. Room (2010)). 
Практическая значимость работы: материалы исследования могут быть использованы при изучении спецкурсов по практике научных исследований, ономастике и лексикологии в гуманитарных вузах. Полученные результаты могут быть отражены в учебных и методических пособиях по проведению ономастических исследований.

\section{Основная часть}

Во второй половине XIX в. в англоязычных странах началась масштабная инвентаризация авторских псевдонимов. В языкознании такая инвентаризация именуется ономатографией, трактуемой как «записывание имен» (Подольская, 1978, с. 104).

Суть ономатографического подхода заключается в составлении словарей и справочников различных видов онимов (имен собственных), в том числе и псевдонимов, без описания их графико-фонетических и этимологических особенностей, а также указания на авторскую интенцию. Одним из первых таких сборников является словарь американских и английских авторских псевдонимов, выпущенный в 1888 году Уильямом Кушингом (William Cushing): он охватывает период с 1700 по 1885 год и представляет собой колоссальное собрание инициалов, подписей и псевдонимов - около 12000.

В рамках вышеупомянутого подхода одни ономатографы предпочитали охватывать как можно больше еще не обработанного ономастического материала. Так, изданный в 1925 году Уильямом Эбботтом (William Abbatt) словарь “The Colloquial Who's who: An Attempt to Identify the Many Authors, Writers and Contributors who Have Used Pen-names, Initials, Etc. (1600-1924)” состоит из двух томов: первый включает в себя американские и канадские литературные псевдонимы, прозвища и клички, а второй - соответствующие номинативные единицы, относящиеся к британским авторам.

Другие составители ограничивались одной страной (H. Scadding (1877)) или занимались псевдонимами отдельного литератора (A. Friedman (1946)), либо авторов, которые направляли свои статьи в периодические издания (W. Copinger (1919), H. Shine (1949)).

В настоящее время наблюдается заметное сокращение масштабов инвентаризации англоязычных авторских псевдонимов. Словари становятся более «универсальными» за счет включения в них сценических имен музыкантов, прозвищ политиков, деятелей искусства и т.д. Эта тенденция привела к тому, что на сегодняшний день выпуск справочников по англоязычным авторским псевдонимам практически прекратился, и труд Теренса Кэрти (Terence Carty) “A Dictionary of Literary Pseudonyms in the English Language” (2000) фактически является единственным современным сборником подобного рода.

B XX в. на фоне вышеупомянутой инвентаризации к изучению авторских псевдонимов приступают литературоведы, которые рассматривали и продолжают рассматривать данные единицы не только как элемент творческого инструментария литератора, но еще и как своеобразный маркер различных аспектов жизни населения Великобритании и других англоязычных стран, а именно - политических, исторических, гендерных, социально-бытовых и прочих. Одной из первых работ подобного рода стала книга британского биографа Уильяма Кортни (William Courtney) “The Secrets of our National Literature” (1908), в которой он дает оценку авторской псевдонимии в английской литературе XVIII-XIX вв.

Подход зарубежных литературоведов к изучению псевдонимов отличается одной характерной особенностью, которая заключается в том, что между понятиями «псевдонимия» и «анонимность» не проводится четкая граница.

Некоторые исследователи (А. Ferry (2002)), говоря об анонимности, имеют в виду апеллятивные подписи (от термина «апеллятив» - «имя нарицательное в противоположность имени собственному» (Подольская, 1978, с. 36-37)), представляющие собой фразы типа “(by) the author of...”, а также другие незамысловатые словосочетания - “(by) a Lady”, “(by) a Gentleman”, “(by) a Layman”; их можно в большом количестве обнаружить в словарях англоязычных авторских псевдонимов разных эпох.

Существует мнение о том, что псевдонимия «находится в подчинении» у анонимности, поскольку «автор сначала создает текст, а уже потом указывает на нем имя, обозначая тем самым его принадлежность» (Raven, 2003, с. 38). Эта идея послужила основой для толкования псевдонимии как подкатегории анонимности.

В отечественном литературоведении и языкознании дифференциация соответствующих понятий, несмотря на их смежность, носит однозначный характер. Анонимное произведение считается таковым, если оно публикуется без какого-либо упоминания автора, в то время как обозначенное псевдонимом сочинение обязательно содержит определенную подпись писателя, будь то графический знак, инициалы, апеллятив или имя собственное (Виноградов, 1961).

В отечественном и зарубежном языкознании есть «отдельный раздел, изучающий любые имена собственные - ономастика» (Подольская, 1978, с. 97), получившая статус науки в 1930-х годах (Ономастика, 2021). Ономастический подход ориентирован на проведение научного поиска по таким направлениям, как: «...определение специфики значения имени собственного (онима), его отличий от имени нарицательного; описание сходств и различий между разрядами ономастических номинаций и выявление принципов их классификации; определение места ономастической лексики в системе языка; противопоставление понятий естественной и искусственной номинации; применение по́левого метода к ономастическим исследованиям; исследование проблем коннотативности и прецедентности имени собственного; изучение динамики становления и развития антропонимиконов и др.» (Буркова, 2016, с. 8-10). 
Отдельно выделяют аспекты ономастических исследований:

- «лексикографический аспект преследует цели лексикографирования имен собственных;

- лексикологический аспект прежде всего предполагает описание имен собственных какого-либо языка в его лексической системе, показ их места в структуре данного языка, их генетический анализ, их сравнение с апеллятивами;

- географический аспект предполагает картографирование имен;

- историко-культурный аспект имеет в виду изучение того национально-культурного фона, на котором возникают имена;

- исторический аспект направлен на анализ исторического фона, на котором складывались и формировались ономастические системы и др.» (Суперанская, Сталтмане, Подольская и др., 2019, с. 221-230).

Анализ изданных в разное время зарубежных трудов по ономастике (M. Ezell (1994), A. Fowler (2012), J. Clarke (1977) и др.) показывает, что тема англоязычных писательских псевдонимов носит в них главным образом декларативный характер и не подвергается глубокому анализу.

В современных отечественных ономастических трудах псевдонимия в той или иной степени освещается в контексте изучения семантико-прагматических и стилистических особенностей имен собственных (Е. А. Москаленко (2012), Е. Ю. Рубцова (2006) и др.), объектом изучения может становиться ономастикон («репертуар собственных имен для данного этноса, социума, периода» (Подольская, 1978, с. 98)) в произведениях одного или нескольких писателей (Е. А. Лебедева (2006)). Однако стоит отметить, что тема псевдонимии раскрывается преимущественно в обзорно-теоретических главах таких исследований, и, соответственно, остается неизученным большой объем инвентаризированного материала.

В настоящем исследовании рассматривается лексикологический аспект англоязычных авторских псевдонимов (то есть их место в системе онимов) в русле по́левых исследований.

В английском языке совокупность онимов можно представить в виде по́левой структуры.

В языкознании «поле представляет собой такое построение, при котором соответствующая грамматическая единица обладает центром и периферией. Центр образуется при этом оптимальной концентрацией всех совмещающихся в данной единице признаков. Периферия состоит из большего или меньшего числа образований разной емкости (иногда сводящихся к отдельному слову или форме слова) с некомплектным числом этих признаков, то есть с отсутствием одного или нескольких из них, или при их измененной интенсивности, и с факультативным наличием других признаков» (Адмони, 1964, с. 49).

Признаки имени собственного состоят в следующем: «1) оно дается индивидуальному объекту, а не классу объектов, имеющих черту, характерную для всех индивидов, входящих в этот класс; 2) именуемый с помощью имени собственного объект всегда четко определен, ограничен, очерчен; 3) оно не связано непосредственно с понятием и не имеет на уровне языка четкой и однозначной коннотации» (Суперанская, 2009, с. 324).

Таким образом, «ядро антропонимии составляют личные имена и их гипокористические (краткие, домашние) формы. Уменьшительно-ласкательные и увеличительно-уничижительные формы, а также отчества и фамилии располагаются в околоядерном пространстве с разной степенью движения в сторону периферии, а прозвища и псевдонимы образуют антропонимическую периферию.

Псевдонимы располагаются на периферии, поскольку они относятся к разрядам имен собственных, имеющих структурно-семантическое разнообразие и обладающих чертами апеллятивно-онимического пограничья» (Супрун, 2000, с. 7-12).

Однако отличительная черта англоязычных авторских псевдонимов состоит в том, что «фундаментом» для них служат как различные виды онимов, так и апеллятивы - «имена нарицательные в противоположность именам собственным» (Подольская, 1978, с. 36-37).

Так, ядро поля англоязычных авторских псевдонимов составляют номинативные единицы, созданные в соответствии с традициями именования англоязычных стран, то есть те, что представляют собой:

- имена (и их краткие формы) в сочетании с фамилиями: Reginald Crunden - Hylton Reginald Cleaver (1891-1961); Gwen Priestwood - Gwendoline Ethel Nelson (1923-year);

- только имена: Rosa - Rosa Vertner Griffith Johnson Jeffrey (1828-1894); Bettina - Bettina Ehrlich (1903-1985);

- только фамилии: Sutton - John Sutton (1820-1873); Blair - Wallace Wilfrid Blair-Fish (1889-1968).

В околоядерном пространстве находятся англоязычные авторские псевдонимы, состоящие из диминутивов имен как в сочетании с фамилией, так и без нее: Kitty Connor - James McKowen, (1814-1889); Gussie Augusta Chambers (1863-1900).

Периферию занимают псевдонимы, построенные на прозвищах и апеллятивах: Bon Viveur (прозвище от франц. «живущий в свое удовольствие») - Christopher Wentworth Dilke (1913-1987); A Farmer and a Breeder John Lawrence (1753-1839).

Кроме того, стоит отметить англоязычные авторские псевдонимы, в состав которых входят:

- имена и апеллятивы: Frank Somebody - Charles Lucas (1713-1771); John Ploughman - Charles Haddon Spurgeon (1834-1892);

- имена и прозвища: Alan Caillou (фамилия представляет собой прозвище, полученное во время службы в армии; от франц. «камень») - Alan Samuel Lyle-Smythe (1914-2006);

- прозвища и апеллятивы: A Real Paddy (второй апеллятив представляет собой прозвище ирландцев (Paddy, 2021)) - Pierce Egan (1772-1849). 
Таким образом, англоязычные авторские псевдонимы могут быть не только проприальными (онимическими) или апеллятивными, но и, судя по примерам, занимать промежуточное звено между этими двумя категориями.

\section{Заключение}

Значительный период истории изучения англоязычных авторских псевдонимов занимают ономатографические и литературоведческие изыскания. Первые заключаются исключительно в сборе и упорядочивании эмпирического материала без анализа его этимологии, а вторые предполагают экскурс в историю становления и развития псевдонимии в англоязычной литературе разных времен, при этом упор делается на изучении творческого пути автора. Ономастический подход ориентирован на изучение различных аспектов возникновения и существования широкого спектра онимов, в том числе и псевдонимов. Они упоминаются во многих современных ономастических исследованиях, однако их авторы не заостряют внимание на этих номинативных единицах.

Англоязычные авторские псевдонимы формируют собственное языковое поле, охватывая другие виды онимов (имена и их гипокористические формы, фамилии, прозвища), а также апеллятивы. Оно имеет все присущие ему атрибуты - ядро, околоядерное пространство и периферию: распределение псевдонимов между ними происходит в зависимости того, насколько отчетливо в них проявляются признаки имени собственного и насколько далеко они отступают от канонов именования англоязычных стран. Представляется целесообразным распределить англоязычные авторские псевдонимы на три категории, исходя из языковых единиц, входящих в их состав: проприальные псевдонимы (состоят из онимов), апеллятивные псевдонимы (состоят из апеллятивов) и проприально-апеллятивные псевдонимы (состоят как из онимов, так и из апеллятивов).

Перспективы дальнейшего исследования англоязычных писательских псевдонимов мы видим в их изучении в рамках когнитивной лингвистики, одного из передовых направлений современного языкознания, а точнее концепций когнитивного исследования смыслового варьирования псевдонимов (речь идет о теории концептуальной метафоры, теории концептуального блендинга, теории референции (Нахимова, 2010)).

\section{Источники | References}

1. Адмони В. Г. Основы теории грамматики. М.: Наука, 1964.

2. Буркова Т. А. Современные ономастические исследования. Уфа: ИПК БГПУ, 2016.

3. Виноградов В. В. Проблема авторства и теория стилей. М.: Гослитиздат, 1961.

4. Лебедева Е. А. Ономастикон произведения Дж. Р. Р. Толкина «Властелин Колец»: структурный, семантический и функциональный аспекты: автореф. дисс. ... к. филол. н. Ростов-на-Дону, 2006.

5. Москаленко Е. А. Функционально-прагматические особенности неофициальных именований лица: на материале английского и русского языков: автореф. дисс. ... к. филол. н. Ставрополь, 2012.

6. Нахимова Е. А. Аспекты когнитивного исследования использования имени собственного // Вопросы когнитивной лингвистики. 2010. № 2 (23).

7. Ономастика. 2021. URL: https://bigenc.ru/linguistics/text/2689763

8. Подольская Н. В. Словарь русской ономастической терминологии. М.: Наука, 1978.

9. Рубцова Е. Ю. Прагматическое содержание антропонимов: на материале русского и английского языков: дисс. ... к. филол. н. Ростов-на-Дону, 2006.

10. Суперанская А. В. Общая теория имени собственного. М.: Либроком, 2009.

11. Суперанская А. В., Сталтмане В. Э., Подольская Н. В. и др. Теория и методика ономастических исследований. M.: URSS, 2019.

12. Супрун В. И. Ономастическое поле русского языка и его художественно-эстетический потенциал: автореф. дисс. ... д. филол. н. Волгоград, 2000.

13. Carty T. J. A Dictionary of Literary Pseudonyms in the English Language. 2nd ed. L.: Mansell, 2000.

14. Clarke J. Pseudonyms: the names behind the names. Nashville: Thomas Nelson Publishers, 1977.

15. Copinger W. On the Authorship of the First Hundred Numbers of the "Edinburgh Review". Chicago: The University of Chicago Press, 1919.

16. Ezell M. Reading Pseudonyms in Seventeenth-Century English Coterie Literature // Essays in Literature. 1994. Vol. 21. № 1.

17. Ferry A. “Anonymity”: The Literary History of a Word // New Literary History. 2002. Vol. 33. № 2.

18. Fowler A. Literary Names: Personal Names in English Literature. Oxford: Oxford University Press, 2012.

19. Friedman A. Oliver Goldsmith’s Contributions to the “Critical Review” // Modern Philology. 1946. Vol. 44 . № 1.

20. Paddy. 2021. URL: https://www.etymonline.com/search?q=Paddy

21. Raven J. The Anonymous Novel in Britain and Ireland, 1750-1830 // The Faces of Anonymity: Anonymous and Pseudonymous Publication from the Sixteenth to the Twentieth Century / ed. by R. J. Griffin. N. Y.: Palgrave Macmillan, 2003.

22. Room A. Dictionary of Pseudonyms: 13,000 Assumed Names and Their Origins. Jefferson: McFarland \& Co., 2010.

23. Scadding H. Some Canadian noms-de-plume identified. Toronto: Copp, Clark \& Co., 1877.

24. Shine H. The Quarterly Review under Gifford. Identification of Contributors, 1809-1824. Chapel Hill: University of North Carolina press, 1949. 


\section{Информация об авторах | Author information}

\section{RU Сидоров Андрей Владимирович ${ }^{1}$}

${ }^{1}$ Российский государственный педагогический университет им. А. И. Герцена, г. Санкт-Петербург

EN Sidorov Andrei Vladimirovich ${ }^{1}$

${ }^{1}$ Herzen State Pedagogical University, St. Petersburg

${ }^{1}$ andrewseadorov@gmail.com

\section{Информация о статье | About this article}

Дата поступления рукописи (received): 04.10.2021; опубликовано (published): 30.11.2021.

Ключевые слова (keywords): псевдоним; апеллятив; оним; ономастика; ономатография; pseudonym; appellative; onym; onomastics; onomatography. 